\title{
RECOMENDAÇÃO DE ADUBAÇÃO NITROGENADA PARA TRIGO EM SUCESSÃO AO MILHO E SOJA SOB SISTEMA PLANTIO DIRETO NO PARAGUAI ${ }^{(1)}$
}

\author{
Ademir Wendling( ${ }^{(2)}$, Flávio Luiz Foletto Eltz ${ }^{(3)}$, Martin Maria Cubilla ${ }^{(4)}$, Telmo \\ Jorge Carneiro Amado ${ }^{(5)}$, João Mielniczuk ${ }^{(6)} \&$ Thome Lovato $^{(7)}$
}

\begin{abstract}
RESUMO
O nitrogênio (N) é um dos nutrientes mais requeridos pelo trigo e, muitas vezes, não é suprido nem na quantidade nem na época ideal. Devido à importância da adubação nitrogenada no trigo e à carência de informações disponíveis no Paraguai, foi desenvolvido este trabalho com o objetivo de propor uma recomendação nitrogenada para trigo sob sistema plantio direto. Cinco experimentos em rede foram realizados a campo, durante dois anos, em três departamentos do Paraguai, abrangendo os principais solos (Oxisols, Inceptisols e Ultisols) e regiões produtoras (Alto Paraná, Itapúa e Missiones). Os tratamentos utilizados no trigo (Triticum aestivum) foram cinco doses de $\mathrm{N}\left(0,30,60,90\right.$ e $\left.120 \mathrm{~kg} \mathrm{ha}^{-1}\right)$ após o milho (Zea mays) e a soja (Glycine max), sendo também investigado o efeito residual de $\mathrm{N}$ aplicado no milho $\left(0,60,120,180\right.$ e $\left.240 \mathrm{~kg} \mathrm{ha}^{-1}\right)$ na nutrição do trigo, em parcelas de $5 \times 8 \mathrm{~m}$, em delineamento de blocos ao acaso com três repetições. $O$ trigo respondeu economicamente, em média, à dose de $35 \mathrm{~kg} \mathrm{ha}^{-1}$ de $\mathrm{N}$ após a soja para produtividades em torno de $3.100 \mathrm{~kg} \mathrm{ha}^{-1}$; após o milho, respondeu economicamente, em média, até $30 \mathrm{~kg} \mathrm{ha}^{-1} \mathrm{de} \mathrm{N}$, atingindo produtividade de $2.100 \mathrm{~kg} \mathrm{ha}^{-1}$. No solo com teor de matéria orgânica maior que $4 \%$, verificou-se capacidade de suprir, sem adubação nitrogenada mineral, quantidade suficiente de $\mathrm{N}$ para alcançar produtividades de até $2.500 \mathrm{~kg} \mathrm{ha}^{-1}$. $\mathrm{O}$ trigo respondeu à adubação resi-
\end{abstract}

\footnotetext{
(1) Parte da Tese de Mestrado do primeiro autor. Financiado pela Câmara Paraguaia de Exportadores de Cereais e Oleaginosas CAPECO. Recebido para publicação em fevereiro de 2006 e aprovado em maio de 2007.

${ }^{(2)}$ Mestre em Ciência do Solo, BASE Precisão na Agricultura. Av. Roraima 03, Caixa Postal 5053, CEP 97110-970 Santa Maria (RS). E-mail: ademir@baseap.com.br

(3) Professor Titular do Departamento de Solos da Universidade Federal de Santa Maria - UFSM. CEP 97110-970 Santa Maria (RS), Bolsista do CNPq. E-mail: feltz@ccr.ufsm.br

(4) Mestre em Ciência do Solo, UFSM.

(5) Professor Adjunto do Departamento de Solos, UFSM. Bolsista do CNPq. E-mail: tamado@ccr.ufsm.br

(6) Professor Colaborador, Universidade Federal do Rio Grande do Sul - UFRGS. Av. Bento Gonçalves 7712, CEP 91540-000 Porto Alegre (RS). Bolsista do CNPq. E-mail: mieln@vortex.ufrgs.br

(7) Professor Adjunto do Departamento de Solos, UFSM. E-mail: thlovato@ccr.ufsm.br
} 
dual de $\mathrm{N}$ aplicado no milho, elevando a produtividade de 1.800 (0 kg ha-1) para $2.300 \mathrm{~kg} \mathrm{ha}^{-1}$ (com a dose estimada de $213 \mathrm{~kg} \mathrm{ha}^{-1} \mathrm{de} \mathrm{N}$ aplicado no milho, na média de todos os locais).

Termos de indexação: curvas de resposta, máxima eficiência técnica, máxima eficiência econômica, fertilidade do solo, sucessão de culturas.

\title{
SUMMARY: NITROGEN FERTILIZER RECOMMENDATION FOR NO-TILL WHEAT IN SUCCESSION TO CORN AND SOYBEAN IN PARAGUAY
}

\begin{abstract}
Nitrogen is one of the nutrients wheat needs most, but is often not supplied neither in the right quantity nor at the right time. Because of the importance of nitrogen fertilization and the lack of information available in Paraguay, this study was developed to establish a nitrogen fertilizer recommendation for wheat under no-till. Six field experiments were carried out over a period of two years, in four Departments of Paraguay, considering the most important soils (Oxisols, Inceptisols and Ultisols) and regions (Alto Paraná, Itapúa, Amambay and Missiones). Five $N$ rates $\left(0,30,6090,120 \mathrm{~kg} \mathrm{ha}^{-1}\right)$ were applied to wheat (Triticum aestivum) after corn (Zea mays) and soybean (Glycine max), and the residual effect on wheat of $N$ applied to the precedent corn crop was evaluated (0,60, 120, 180 and $\left.240 \mathrm{~kg} \mathrm{ha}^{-1}\right)$, in $5 \times 8 \mathrm{~m}$ plots, in a random block design with three replications. Economically, wheat after soybean responded positively to the $N$ rate of $35 \mathrm{~kg} \mathrm{ha}^{-1}$ with yields around $3.100 \mathrm{~kg} \mathrm{ha}$. After corn, wheat responded economically to doses of up to $30 \mathrm{~kg} \mathrm{ha}^{-1} \mathrm{~N}$ and reached a grain yield of $2.100 \mathrm{~kg} \mathrm{ha}^{-1}$. When the concentration of soil organic matter is higher than $4 \%$, a sufficient quantity of $N$ is available without mineral $N$ fertilization, for yields up to $2.500 \mathrm{~kg} \mathrm{ha}^{-1}$. Wheat responded to residual $N$ applied to corn with a yield increase from $1.800 \mathrm{~kg} \mathrm{ha}^{-1}\left(0 \mathrm{~kg} \mathrm{ha}^{-1}\right)$ to $2.300 \mathrm{~kg} \mathrm{ha}^{-1}$ ( $N$ applied to corn estimated at $213 \mathrm{~kg} \mathrm{ha}^{-1}$, averaged across all sites).
\end{abstract}

Index terms: yield response, maximum technical efficiency, maximum economical efficiency, soil fertility, crop succession.

\section{INTRODUÇÃO}

$\mathrm{O} \mathrm{N}$, por ser absorvido em grande quantidade pelo trigo, comumente não é suprido na quantidade necessária e no estádio fisiológico requerido. O suprimento adequado do $\mathrm{N}$ no sistema plantio direto (SPD) é mais complexo do que no sistema convencional de cultivo (SCC). A principal razão para isso está relacionada com a quantidade e qualidade de resíduos da cultura anterior remanescente sobre o solo, podendo disponibilizar ou imobilizar $\mathrm{N}$ para a cultura subseqüente. $\mathrm{O}$ suprimento do $\mathrm{N}$ para as culturas não-leguminosas tem importância econômica e ambiental muito significativa, pela alta resposta à aplicação e facilidade de perda, ocasionando contaminação ambiental.

$\mathrm{O}$ trigo tem apresentado resposta significativa à aplicação de N (Goepfert et al., 1974). Em média, exporta em torno de $22 \mathrm{~kg} \mathrm{ha}^{-1}$ de N (CQFSRS/SC, 2004) por tonelada de grãos retirados da lavoura. Para que não ocorra redução do estoque de $\mathrm{N}$ no solo, é importante que essa quantidade seja reposta em alguma fase do sistema produtivo.
O Paraguai cultiva grandes áreas com trigo e com milho e tem à disposição uma recomendação lançada no ano de 1999 (Fatecha, 1999), que foi desenvolvida para o SCC. Os agricultores paraguaios usam também, alternativamente, recomendações de diversas regiões do Brasil, sobretudo as do Rio Grande do Sul e Paraná. Devido à importância da adubação nitrogenada para o trigo e à carência de informações disponíveis no país, uma recomendação de $\mathrm{N}$ ajustada para o SPD é fundamental para o aumento da produtividade desta cultura $\mathrm{O}$ objetivo deste trabalho foi obter informações para elaborar uma recomendação de adubação nitrogenada para o trigo sob SPD no Paraguai.

\section{MATERIAL E MÉTODOS}

Foram realizados cinco experimentos em diferentes regiões do Paraguai, sendo um no Departamento de Misiones (M1), dois no Departamento de Itapúa (I1 e I2) e dois no Departamento do Alto Paraná (AP1 e AP2) (Quadro 1). Utilizou-se a Classificação 
Americana de Solos, que é a usada no Paraguai, e também a classificação correspondente brasileira.

O experimento M1 é uma área cultivada há vários anos sob plantio direto, com algumas retiradas de silagem para alimentação animal. O experimento I1 foi implantado numa área sob plantio direto há mais de 15 anos, com alto incremento anual de massa seca. $\mathrm{O}$ experimento I2 foi implantado sob uma área em pousio invernal com baixa quantidade de palha sobre a superfície, submetida à intensa degradação quando se encontrava sob sistema convencional de cultivo. $\mathrm{O}$ experimento AP1 foi instalado em área sob condução do sistema plantio direto com alto incremento de massa seca. O experimento AP2 foi estabelecido em área cultivada sob sistema plantio direto, porém recebendo baixa dose de adubações, pois se encontrava sob arrendamento. Apesar disso, apresenta altos valores de matéria orgânica (MO).

O delineamento experimental utilizado foi de blocos ao acaso, com três repetições. A dimensão das parcelas experimentais foi de $5 \times 8 \mathrm{~m}$. Os tratamentos aplicados para cultura do trigo no ano de 2003 (a cultura anterior foi a soja, conduzida pelos agricultores) consistiram de quatro doses de $\mathrm{N}(0,30$, 60 e $90 \mathrm{~kg} \mathrm{ha}^{-1}$ ), sendo essa adubação efetuada no perfilhamento das plantas. Em 2004 foi acrescentada a dose de $120 \mathrm{~kg} \mathrm{ha}^{-1}$ e foram realizados experimentos sobre resteva de milho e soja. As parcelas sobre a resteva de milho apresentavam residual de tratamentos aplicados ao milho (0, 60, 120, 180 e
$240 \mathrm{~kg} \mathrm{ha}^{-1}$ de N) e foram divididas em duas partes: uma que recebeu as doses normais de $\mathrm{N}$ e a outra, somente o residual mais as quantidades mineralizadas no solo. A adubação nitrogenada foi parcelada, sendo aplicados $15 \mathrm{~kg} \mathrm{ha}^{-1}$ na semeadura e o restante no perfilhamento do trigo.

As semeaduras foram feitas nas épocas recomendadas, objetivando atingir a máxima produção das culturas, sendo efetuadas em meados de maio em ambos os anos (2003 e 2004). Em 2003, foram semeadas a cultivar Itapúa 40 em M1 e Itapúa 50 em I1. Em 2004, semeou-se a cultivar Itapúa 40 em todos os experimentos, à exceção de AP2. O trigo de safra de 2003 foi semeado sob a resteva de soja cultivada pelos produtores.

As adubações de $\mathrm{P}$ e $\mathrm{K}$ foram aplicadas a lanço, na dose de $100 \mathrm{~kg} \mathrm{ha}^{-1}$ de $\mathrm{P}_{2} \mathrm{O}_{5}$ e $75 \mathrm{~kg} \mathrm{ha}^{-1}$ de $\mathrm{K}_{2} \mathrm{O}$. As fontes utilizadas foram o superfosfato triplo (46\% de $\left.\mathrm{P}_{2} \mathrm{O}_{5}\right)$ e o cloreto de potássio $\left(60 \%\right.$ de $\left.\mathrm{K}_{2} \mathrm{O}\right)$. A fonte de $\mathrm{N}$ foi a uréia ( $45 \%$ de $\mathrm{N}$ ), tanto na semeadura como em cobertura. Os tratos culturais foram efetuados para a cultura expressar seu máximo potencial produtivo.

As colheitas de trigo ocorreram no mês de setembro nos respectivos anos, e as produtividades, corrigidas para $13 \%$ de umidade no grão. Para determinação da produtividade de grãos, foram coletadas, no trigo cultivado em 2003, três amostras de $0,25 \mathrm{~m}^{2}$, totalizando 0,75 $\mathrm{m}^{2}$ por parcela. Em 2004, foi coletada uma área de $3,2 \mathrm{~m}^{2}$ por parcela.

Quadro 1. Classificação dos solos, posição geográfica dos experimentos, características químicas, teor de argila na camada de 0-10 cm e histórico de manejo nos locais, antes da instalação dos experimentos Paraguai, 2005

\begin{tabular}{|c|c|c|c|c|c|c|c|c|c|c|}
\hline \multirow{2}{*}{ Local } & \multicolumn{2}{|c|}{ Classificação do solo } & \multicolumn{2}{|c|}{ Posição geográfica } & \multirow{2}{*}{$\begin{array}{c}\mathrm{pH} \\
\mathrm{H}_{2} \mathrm{O}\end{array}$} & \multirow{2}{*}{ Argila } & \multirow{2}{*}{ MO } & \multirow{2}{*}{$\mathbf{P}$} & \multirow{2}{*}{$\mathbf{K}$} & \multirow{2}{*}{$\begin{array}{l}\text { Histórico de } \\
\text { manejo }\end{array}$} \\
\hline & Brasileira & Americana & Latitude & Longitude & & & & & & \\
\hline & & & & & & \multicolumn{2}{|c|}{$-\mathrm{g} \mathrm{kg}^{-1}-$} & \multicolumn{2}{|c|}{$-\mathrm{mgdm} \mathrm{m}^{-3}-$} & \\
\hline M1 & Argissolo & Ultisol & $26^{\circ} 59^{\prime} 55,29266^{\prime \prime}$ & $56^{\circ} 45^{\prime} 01,75456^{\prime \prime}$ & 5,2 & 250 & 25 & 11,9 & 47 & $\begin{array}{c}\text { PD estabelecido } \\
\text { Retiradas de silagem }\end{array}$ \\
\hline $\mathrm{I} 1$ & Latossolo & Oxisol & $26^{\circ} 56^{\prime} 07,09384$ " & $55^{\circ} 38^{\prime} 03,81347^{\prime \prime}$ & 5,6 & 475 & 30 & 12,7 & 206 & $\begin{array}{c}\text { PD estabelecido } \\
\text { Alta adição de palha }\end{array}$ \\
\hline $\mathrm{I} 2$ & Argissolo & Ultisol & $27^{\circ} 08^{\prime} 54,11744^{\prime \prime}$ & $56^{\circ} 03^{\prime} 46,26738^{\prime \prime}$ & 6,2 & 355 & 25 & 3,5 & 195 & $\begin{array}{l}\text { PD sem cobertura } \\
\text { Pousio invernal }\end{array}$ \\
\hline AP1 & Latossolo & Oxisol & $25^{\circ} 27^{\prime} 23,15682^{\prime \prime}$ & $55^{\circ} 02^{\prime} 49,16350^{\prime \prime}$ & 5,3 & 395 & 29 & 7,6 & 203 & $\begin{array}{l}\text { PD estabelecido } \\
\text { Alta adição de palha }\end{array}$ \\
\hline AP2 & Latossolo & Alfisol & $25^{\circ} 58^{\prime} 07,17126^{\prime \prime}$ & $55^{\circ} 12^{\prime} 48,79724 \prime$ & 6,5 & 470 & 42 & 7,9 & 359 & $\begin{array}{l}\text { PD estabelecido } \\
\text { Alta adição de palha }\end{array}$ \\
\hline
\end{tabular}

M1: Misiones 1; I1: Itapúa 1; I2: Itapúa 2, AP1: Alto Paraná 1; AP2: Alto Paraná 2; PD: plantio direto. 
Foram coletadas amostras de solo a $0-10 \mathrm{~cm}$ de profundidade em todos os locais antes do início da implantação dos experimentos, sendo seis amostras compostas (uma amostra composta por bloco) advindas de 10 subamostras cada. $\mathrm{O}$ teor de $\mathrm{MO}$ foi determinado pelo método de oxidação da MO do solo por solução sulfocrômica com calor externo e determinação espectrofotométrica do $\mathrm{Cr}^{3+}$ (Tedesco et al., 1995). Argila, P, K e pH também foram determinados segundo métodos descritos por Tedesco et al. (1995).

Para todos os experimentos foram elaboradas equações que descrevem a resposta das culturas à aplicação do N. Optou-se pela escolha dos modelos polinomiais que se ajustassem melhor aos dados e que fossem adequados à resposta biológica das plantas.

Os valores de máxima eficiência técnica (MET) da utilização do insumo foram calculados a partir da equação de produtividade 1 (equação polinomial quadrática), em que se fez a primeira derivada, e igualando-a a zero, resultando na equação 2. Quando a equação ajustada foi uma polinomial linear positiva, a MET era obtida com utilização da maior dose; em casos de resposta negativa, a MET correspondia à testemunha.

Para determinar a máxima eficiência econômica (MEE), foi utilizada a mesma derivada da equação, multiplicando-se pelo preço do produto (pp) e subtraindo o preço do insumo (pi), resultando na equação 3 (Grimm, 1970; Alvarez V., 1991). Os preços utilizados nos cálculos dos custos são preços médios praticados no Paraguai: U\$ 0,78 kg-1 de N, U\$ $0,10 \mathrm{~kg}^{-1}$ de trigo e U\$ $0,07 \mathrm{~kg}^{-1}$ de milho (informações pessoais obtidas com Nilson Osterlein e Bernardino Orquiola Fernández - preços praticados na COPRONAR e Cooperativa Yguazu, 2004). Dessa forma, a relação pi/pp para trigo ficou em 7,8 , sendo adotada a relação 8 .

Os rendimentos relativos (RR) das culturas foram determinados pela razão entre o fator " $a$ " da equação de regressão polinomial que representa a produtividade sem aplicação do N (testemunha) e a MET calculada a partir da equação e multiplicada por 100 (equação 4).

$$
\begin{gathered}
y=a+b x+c x^{2} \\
\text { dy/dx:. } 0=b+2 c x \\
\text { dy/dx:. } 0=p p(b+2 c x)-p i \\
R R=(\text { fator " } a \text { " da equação *100)/MET }
\end{gathered}
$$

A partir das equações dos experimentos com respostas semelhantes, foram elaboradas equações médias que descrevem a resposta das culturas. Essas equações, juntamente com dados de literatura, foram a base utilizada na elaboração da recomendação de $\mathrm{N}$ para o trigo sob sistema plantio direto no Paraguai, a qual foi ajustada em reunião da RENALAS (2005).

\section{RESULTADOS E DISCUSSÃO}

\section{Produtividade de trigo após a soja}

Na safra de 2003, foram realizados experimentos de trigo após a soja em apenas dois locais (M1 e I1). A produtividade do trigo em I1 (4.204 $\left.\mathrm{kg} \mathrm{ha}^{-1}\right)$ foi muito superior à obtida em M1 (1.701 kg ha-1) (Quadro 2). Essa diferença se deve à ocorrência de déficit hídrico em M1 (Quadro 3), que prejudicou o rendimento, e a diferença histórica de uso do solo entre esses dois locais. Além disso, I1 encontrava-se no sistema plantio direto por vários anos, o que favoreceu a produção de palhada, resultando em boa estruturação do solo e, com isso, um histórico de altas produtividades, enquanto M1 é uma área com baixo teor de $\mathrm{MO}$ e em que ocorreram retiradas de massa verde para silagem.

Apesar dessa diferença, os dois locais apresentaram resposta à aplicação de N: em I1 houve incremento maior no rendimento do trigo, chegando a $635 \mathrm{~kg} \mathrm{ha}^{-1}$, com fator "b" da equação de 20,02, enquanto em M1 houve incremento de $331 \mathrm{~kg} \mathrm{ha}{ }^{-1}$, com fator "b" de 11,80. Resultado semelhante ao do I1 foi obtido por Mundstock \& Bredemeier (2002), em estudo sobre as épocas e doses de aplicação de N para o trigo, utilizando diferentes doses na emergência e $40 \mathrm{~kg} \mathrm{ha}^{-1}$ de $\mathrm{N}$ em cobertura, na sétima folha; a aplicação em cobertura resultou em aumento da produtividade em até $730 \mathrm{~kg} \mathrm{ha}^{-1}$, em relação à não-aplicação.

Na safra de trigo de 2004, a resposta à aplicação de $\mathrm{N}$ também foi distinta nos experimentos; houve incremento na produtividade com as doses aplicadas, menos em I1 e I2 (Quadro 2). O experimento M1 não apresentou resposta à aplicação de N; ao contrário, a produtividade decresceu com as doses. Neste experimento, após a colheita de soja, houve compactação do solo pelo tráfego de máquinas na área, o que, juntamente com o déficit hídrico (Quadro 3) ocorrido também em 2004, provavelmente explica a ausência de resposta do trigo ao $\mathrm{N}$.

O experimento I1, em 2004, não atingiu a mesma produtividade que na safra de 2003. Contudo, novamente a cultura apresentou resposta às doses de $\mathrm{N}$, atingindo a produtividade máxima com a dose de $91 \mathrm{~kg} \mathrm{ha}^{-1}$ de N. Esse comportamento distinguiu-se dos experimentos do Alto Paraná (AP1 e AP2), onde os solos foram capazes de suprir $\mathrm{N}$ para produtividade de até $2.800 \mathrm{~kg} \mathrm{ha}^{-1}$, com semelhante teor de MO e palhada de soja. Pode ter contribuído para essa menor produtividade em M1 o fato de esta ter sido a segunda safra consecutiva de trigo na mesma área, na qual se constatou incremento nos sintomas de doenças. Este experimento também apresentou, em valores absolutos, menor produtividade de soja $\left(2,8 \mathrm{t} \mathrm{ha}^{-1}\right)$ que os experimentos AP1 e AP2, deixando, conseqüentemente, menor palhada sobre a superfície, ou seja, menor quantidade de $\mathrm{N}$ liberado com a decomposição dos resíduos. 
Quadro 2. Equações de produtividade, coeficiente de determinação, máxima eficiência técnica (MET) e produtividade de trigo como variável das doses de N aplicadas após cultivo da soja - safras de 2003 e 2004

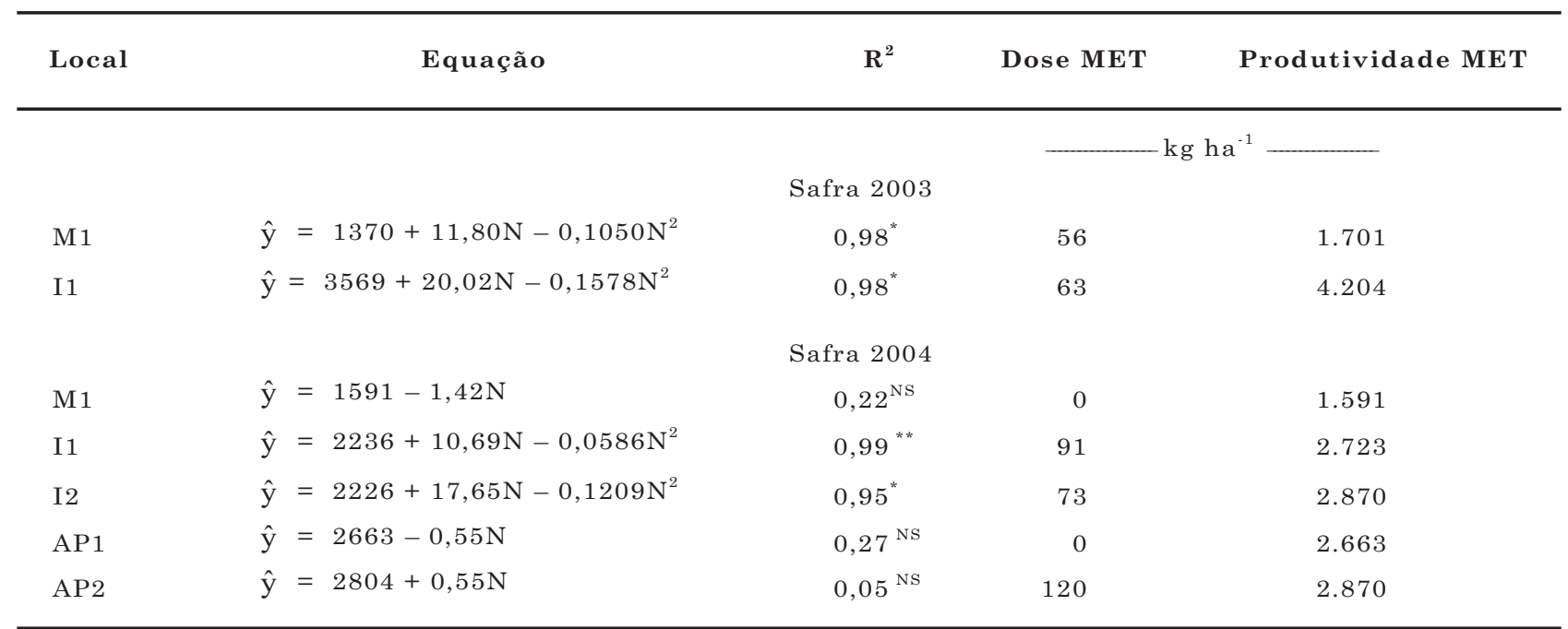

y: rendimento esperado, em kg ha ${ }^{-1}$; N: dose de nitrogênio, em kg ha-1; M1: Misiones 1; I1: Itapúa 1; I2: Itapúa 2; AP1: Alto Paraná 1; AP2: Alto Paraná 2. ${ }^{* * *},{ }^{*}{ }^{N S}$ : Significativos a 5 e $10 \%$ de erro e não-significativo, respectivamente.

Quadro 3. Precipitações ocorridas em Carmen del Paraná e Iguazu nas safras de trigo de 2003 e 2004

\begin{tabular}{|c|c|c|c|c|c|c|c|c|}
\hline \multirow{2}{*}{$\begin{array}{c}\text { Período } \\
\text { mês }\end{array}$} & \multicolumn{4}{|c|}{ Safra 2003 (dia) } & \multicolumn{4}{|c|}{ Safra 2004 (dia) } \\
\hline & $1-10$ & $11-20$ & $21-31$ & Total & $1-10$ & $11-20$ & $21-31$ & Total \\
\hline & \multicolumn{8}{|c|}{ Carmen del Paraná } \\
\hline Abril & 29 & 82 & 52 & 163 & 29 & 39 & 100 & 168 \\
\hline Maio & 0 & 0 & 20 & 20 & 5 & 11 & 64 & 80 \\
\hline Junho & 34 & 45 & 0 & 79 & 33 & 0 & 61 & 95 \\
\hline Julho & 3 & 8 & 0 & 12 & 5 & 60 & 16 & 81 \\
\hline Agosto & 31 & 30 & 33 & 94 & 14 & 1 & 44 & 61 \\
\hline Setembro & 69 & 6 & 19 & 94 & 0 & 40 & 112 & 153 \\
\hline \multirow[t]{2}{*}{ Total } & 165 & 135 & 71 & 241 & 59 & 152 & 334 & 310 \\
\hline & \multicolumn{8}{|c|}{ Iguazu } \\
\hline Abril & 89 & 64 & 0 & 153 & 31 & 36 & 95 & 162 \\
\hline Maio & 63 & 0 & 9 & 72 & 60 & 160 & 207 & 427 \\
\hline Junho & 66 & 14 & 0 & 80 & 12 & 0 & 119 & 131 \\
\hline Julho & 28 & 12 & 0 & 40 & 61 & 158 & 16 & 235 \\
\hline Agosto & 43 & 6 & 18 & 67 & 0 & 0 & 16 & 16 \\
\hline Setembro & 110 & 0 & 162 & 272 & 0 & 54 & 13 & 67 \\
\hline Total & 399 & 96 & 189 & 684 & 164 & 408 & 466 & 1038 \\
\hline
\end{tabular}

No experimento $\mathrm{I} 2$, a resposta às doses de $\mathrm{N}$ elevou a produtividade em até $644 \mathrm{~kg} \mathrm{ha}^{-1}$ com uma dose de $73 \mathrm{~kg} \mathrm{ha}^{-1}$ de N, e o aumento de produtividade por $\mathrm{kg}$ de $\mathrm{N}$ adicionado foi de 17,65 (Quadro 2). Neste experimento, a produtividade de soja $\left(1 \mathrm{t} \mathrm{ha}^{-1}\right)$ e, conseqüentemente, a produção de massa seca foram baixas. Além disso, o teor de MO foi baixo, explicando dessa forma a resposta do trigo às doses de N. Da Ros et al. (2003), estudando épocas de aplicação, encontraram maior aumento na produtividade de trigo, chegando a $1.152 \mathrm{~kg} \mathrm{ha}^{-1}$ com aplicação de $60 \mathrm{~kg} \mathrm{ha}^{-1}$ de $\mathrm{N}$ em cobertura. 
No Departamento do Alto Paraná, o experimento $\mathrm{AP} 1$ não apresentou resposta ao $\mathrm{N}$ após a soja (Quadro 2); entretanto, o experimento AP2 mostrou baixa resposta, alcançando a MET com $120 \mathrm{~kg} \mathrm{ha}^{-1}$ de $\mathrm{N}$, embora não seja econômico. Os solos dos experimentos AP1 e AP2, supostamente, foram capazes de suprir as necessidades de $\mathrm{N}$ do trigo para alcançar a produtividade média de $2.700 \mathrm{~kg} \mathrm{ha}^{-1} \mathrm{de}$ trigo. Estes solos têm teor de MO médio e, além disso, a decomposição da palhada da soja também pode ter disponibilizado significativa quantidade de N (a produtividade da soja foi de $4 \mathrm{t} \mathrm{ha}^{-1}$ ).

Na figura 1 está representada a resposta média (I1 2003 + I1 2004 + I2 2004) do trigo à aplicação de $\mathrm{N}$ após a soja, em solo com teor de $\mathrm{MO}$ menor que $4 \%$. Nessa situação, a resposta máxima do trigo ao $\mathrm{N}$ foi de $76 \mathrm{~kg} \mathrm{ha}^{-1}$ de $\mathrm{N}$, tendo sido produzidos $3.257 \mathrm{~kg} \mathrm{ha}^{-1}$ de grãos (MET). A MEE foi atingida com a dose de $36 \mathrm{~kg} \mathrm{ha}^{-1}$, considerando o pi/pp de 8 , atingindo produtividade de $3.098 \mathrm{~kg} \mathrm{ha}^{-1}$ de grãos. Essa resposta do trigo à aplicação de $\mathrm{N}\left(15,21 \mathrm{~kg}^{\mathrm{h}} \mathrm{H}^{-1}\right.$ de trigo por kg de $\mathrm{N}$ aplicado) é superior à encontrada por Fontoura et al. (2000), que obtiveram retorno de $4,29 \mathrm{~kg} \mathrm{ha}^{-1}$ de trigo por $\mathrm{kg}$ de $\mathrm{N}$ aplicado; contudo, o rendimento inicial obtido por esses autores foi bem superior: $3.760 \mathrm{~kg} \mathrm{ha}^{-1}$ de trigo sem utilização de $\mathrm{N}$. A figura 1 expressa a resposta do trigo ao $\mathrm{N}$ aplicado em condições climáticas favoráveis. Levando em consideração essa informação, recomenda-se a aplicação de $35 \mathrm{~kg} \mathrm{ha}^{-1}$ de $\mathrm{N}$ para o trigo após a soja (solo com 2 a $3 \%$ de MO) em anos que apresentam boas condições climáticas, nos quais a expectativa de produtividade é alta. Essa dose pode ser superior ou inferior em anos em que a relação de pi/pp for mais favorável ou desfavorável, respectivamente, para o produtor.

A dose encontrada neste trabalho está de acordo com a recomendação técnica de N para trigo no Paraná (IAPAR, 1998), que recomenda aplicação de $30 \mathrm{~kg} \mathrm{ha}^{-1}$, sendo $10 \mathrm{~kg} \mathrm{ha}^{-1}$ na semeadura e $20 \mathrm{~kg} \mathrm{ha}^{-1} \mathrm{em}$

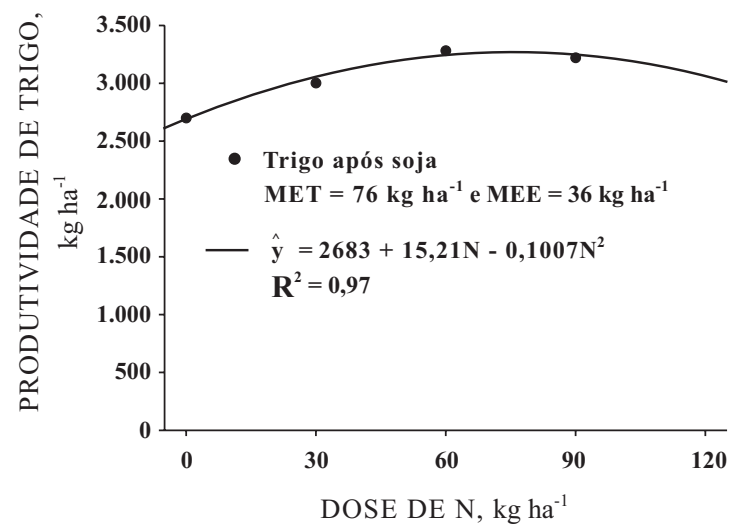

Figura 1. Produtividade de trigo após soja ((I1 2003 + I1 2004 + I2 2004)/3), como variável de doses de $\mathrm{N}$ aplicadas, máxima eficiência técnica (MET) e máxima eficiência econômica (MEE). cobertura. A Comissão (2004) recomenda para o RS e $\mathrm{SC}$ dose de $40 \mathrm{~kg} \mathrm{ha}^{-1}$ de $\mathrm{N}$ para solos com teor médio de MO (2,6-5\%), sendo 15 a $20 \mathrm{~kg} \mathrm{ha}^{-1}$ na semeadura e o restante em cobertura, entre os estádios de afilhamento e de alongamento (aproximadamente 30 a 45 dias após a emergência). Fatecha (1999) recomendou para o Paraguai a aplicação de $20 \mathrm{~kg} \mathrm{ha}^{-1} \mathrm{de} \mathrm{N}$ na semeadura, $40 \mathrm{~kg} \mathrm{ha}^{-1} \mathrm{em}$ cobertura quando o teor de MO for baixo $(<1,2 \%)$ e $30 \mathrm{~kg} \mathrm{ha}^{-1}$ de $\mathrm{N}$ em cobertura quando a MO estiver na faixa média (1,2 a $3,0 \%$ ). Comparando essas recomendações e os resultados encontrados nos experimentos realizados neste trabalho, verifica-se concordância entre eles. Fatecha (1999) alerta para as condições de seca, não recomendando a aplicação de cobertura.

$\mathrm{O}$ experimento conduzido em solo com teor de $\mathrm{MO}$ superior a $4 \%$ não apresentou resposta à aplicação de $\mathrm{N}$ no trigo após a soja, ou seja, o aporte residual da palhada da soja mais as quantidades fornecidas pelo solo foram suficientes para suprir as necessidades da cultura para a produtividade alcançada. Esse resultado pode não se repetir quando produtividades maiores de trigo forem obtidas, considerando que neste experimento os dois anos agrícolas foram afetados por condições climáticas desfavoráveis. Outro fator a ser considerado quando se deseja diminuir as doses desse nutriente é que o $\mathrm{N}$ retirado do sistema pela exportação dos grãos de trigo deverá, de alguma forma, ser reposto ou na forma mineral ou com utilização de leguminosas (adubos verdes) inseridas em um programa de rotação de culturas.

\section{Produtividade de trigo após o milho}

$\mathrm{Na}$ safra de trigo após o milho (Quadro 4), as produtividades foram, em valores absolutos, inferiores às obtidas após a soja (Quadro 2), com exceção do experimento M1. Esses experimentos também apresentaram menor incremento de produtividade com as doses de $\mathrm{N}$ aplicadas (Figura 2).

\section{Produtividade de trigo após o milho como variável do residual de $\mathrm{N}$}

O trigo respondeu ao residual das doses aplicadas no milho (Quadro 4).

$\mathrm{O}$ experimento $\mathrm{M} 1$ apresentou pequeno aumento na produtividade de trigo em razão do residual de $\mathrm{N}$ do milho. Contudo, nesse local, a produtividade alcançada após o milho foi superior, em valores absolutos, à produtividade atingida após a soja. Esse fato não foi observado nos demais experimentos, sendo mais freqüente a maior produtividade após a soja. A provável compactação do solo em decorrência do tráfego de máquinas excessivo pode ser a explicação para o resultado obtido.

No I1, a produtividade atingida após o milho foi inferior à atingida após a soja. Isso indica que a sucessão de gramíneas (trigo/milho/trigo) causou maior efeito negativo à produtividade de trigo do que a 
Quadro 4. Equações da produtividade de trigo, coeficientes de determinação, dose de máxima eficiência técnica (MET) e a produtividade máxima de trigo em função do residual do nitrogênio aplicado no milho - safra de 2004

\begin{tabular}{|c|c|c|c|c|}
\hline Local & Equação & $\mathbf{R}^{2}$ & Dose MET & Produtividade MET \\
\hline & & \multicolumn{3}{|c|}{$\mathrm{kg} \mathrm{ha}^{-1}$} \\
\hline M1 & $\hat{\mathrm{y}}=1694+2,39 \mathrm{~N}-0,0080 \mathrm{~N}^{2}$ & $0,50^{*}$ & 148 & 1.871 \\
\hline I1 & $\hat{y}=1324+1,88 \mathrm{~N}-0,0020 \mathrm{~N}^{2}$ & $0,84^{* * *}$ & 240 & 1.659 \\
\hline $\mathrm{I} 2$ & $\hat{y}=1672+8,13 \mathrm{~N}-0,0128 \mathrm{~N}^{2}$ & $0,99^{* *}$ & 240 & 2.886 \\
\hline AP2 & $\hat{\mathrm{y}}=2524+6,32 \mathrm{~N}-0,0212 \mathrm{~N}^{2}$ & $0,77^{\mathrm{NS}}$ & 149 & 2.995 \\
\hline
\end{tabular}

y: rendimento esperado, em kg ha ${ }^{-1}$; $\mathrm{N}$ : dose de nitrogênio, em kg ha-1; M1: Misiones 1; I1: Itapúa 1; I2: Itapúa 2; AP1: Alto Paraná

1; AP2: Alto Paraná 2. ${ }^{* *},{ }^{* *},{ }^{*} \mathrm{e}^{\mathrm{NS}}$ : Significativos a 1,5 e $10 \%$ e não-significativo, respectivamente.

sucessão gramínea/leguminosa (trigo/soja/trigo). A resposta à adubação residual foi baixa, elevando em $1,87 \mathrm{~kg} \mathrm{ha}^{-1}$ a produtividade do trigo por $\mathrm{kg} \mathrm{ha}^{-1} \mathrm{de} \mathrm{N}$ aplicado no milho. Essa baixa resposta, em parte, pode ser explicada pela alta produtividade obtida no milho, que absorveu e exportou quantidades maiores do $\mathrm{N}$; por isso, o trigo não atingiu a produtividade máxima com o residual da maior dose (Quadro 4).

O experimento I2 apresentou a maior resposta ao residual de $\mathrm{N}$ aplicado no milho, elevando em até $8,13 \mathrm{~kg} \mathrm{ha}^{-1}$ por $\mathrm{kg} \mathrm{ha}^{-1}$ de $\mathrm{N}$, incrementando em $1.214 \mathrm{~kg} \mathrm{ha}^{-1}$ a produtividade obtida com o residual de $240 \mathrm{~kg} \mathrm{ha}^{-1}$. Essa alta resposta está associada à baixa produtividade atingida pelo milho nesse experimento e, conseqüentemente, ao decréscimo na exportação de $\mathrm{N}$ pelos grãos e também à baixa precipitação ocorrida no período, resultando possivelmente em menores perdas de $\mathrm{N}$ por lixiviação. A produtividade com adubação residual foi praticamente igual à atingida com aplicação de $73 \mathrm{~kg} \mathrm{ha}{ }^{-1} \mathrm{de} \mathrm{N}$, após a soja, e $82 \mathrm{~kg} \mathrm{ha-1}$, após o milho.

No AP2, o trigo apresentou resposta ao $\mathrm{N}$ após o milho, que elevou a produtividade em $471 \mathrm{~kg} \mathrm{ha}^{-1} \mathrm{com}$ residual da dose no milho de $149 \mathrm{~kg} \mathrm{ha}^{-1}$. Neste experimento, foi obtido elevado rendimento de milho (8 $\mathrm{t} \mathrm{ha}^{-1}$ ), inclusive no tratamento testemunha, o que provocou, provavelmente, esgotamento das reservas de $\mathrm{N}$ mineral $\left(\mathrm{NH}_{4}-\mathrm{N}\right.$ e $\left.\mathrm{NO}_{3}-\mathrm{N}\right)$ do solo, causando a menor resposta do trigo ao residual após o milho. Considerando a exportação de N pelo milho de $16 \mathrm{~kg}$ de N por tonelada de grãos (CQFSRS/SC, 2004), obtevese quantidade de $128 \mathrm{~kg}$ de $\mathrm{N}$ exportados por hectare.

Essa alta recuperação de N pelo trigo foi decorrente, provavelmente, do curto período de entressafra (45 dias) e das baixas precipitações ocorridas nos períodos de condução do milho, na entressafra e na condução da cultura do trigo. Essa resposta do trigo ao residual das doses aplicadas no milho pode não se repetir todos os anos, pois a baixa precipitação pluvial possivelmente desfavoreceu a lixiviação do N, permanecendo maior quantidade deste nutriente disponível à cultura seguinte. Devido ao curto período de entressafra, não foi utilizada nenhuma planta de cobertura precedendo o trigo. Em estudo realizado no sul do Brasil, quanto à recuperação do $\mathrm{N}$ aplicado no milho, utilizando o nabo forrageiro na entressafra antecedendo ao trigo, Rossato (2004) observou que o residual do $\mathrm{N}$ aplicado no milho aumentou a produção de matéria seca do nabo forrageiro e a produtividade de trigo, sucedendo o nabo, em aproximadamente $8 \%$. Sem a utilização do nabo forrageiro, a diferença de produtividade no trigo foi de apenas $4 \%$.

A resposta média do trigo ao residual das doses aplicadas no milho encontra-se na figura 2. A maior produtividade média de M1, I1, I2 e AP2 foi atingida com $213 \mathrm{~kg} \mathrm{ha}^{-1}$ de $\mathrm{N}$ aplicado no milho, correspondendo a $2.300 \mathrm{~kg} \mathrm{ha}^{-1}$ de grãos de trigo, sendo esta inferior às produtividades atingidas no trigo após soja, porém semelhante à produtividade obtida com aplicação de N no trigo após o milho (Figura 2). Nessa situação, o residual do N aplicado no milho foi capaz de aumentar a produtividade do trigo em aproximadamente $500 \mathrm{~kg} \mathrm{ha}^{-1}$.

Estudos acerca da antecipação de aplicações de N são freqüentes na literatura (Basso, 1999; Lera et al., 2000), com resultados de eficiência de fertilização nitrogenada semelhantes aos deste experimento. A antecipação da fertilização pode ser viável em anos de baixas precipitações pluviais, permitindo dessa forma a recuperação do $\mathrm{N}$ aplicado antecipadamente ou do residual das culturas anteriores. No caso das aplicações nitrogenadas para o trigo após a cultura do milho, por exemplo, essa informação pode ser importante na decisão do suprimento adicional do $\mathrm{N}$, pois em anos de baixa precipitação a adubação poderá ser reduzida consideravelmente. Em anos de precipitação normal há um período para tomada de decisão, a qual poderá ser feita sem prejudicar a produtividade. Os produtores já vêm fazendo observações semelhantes, ou seja, a aplicação de $\mathrm{N}$ 


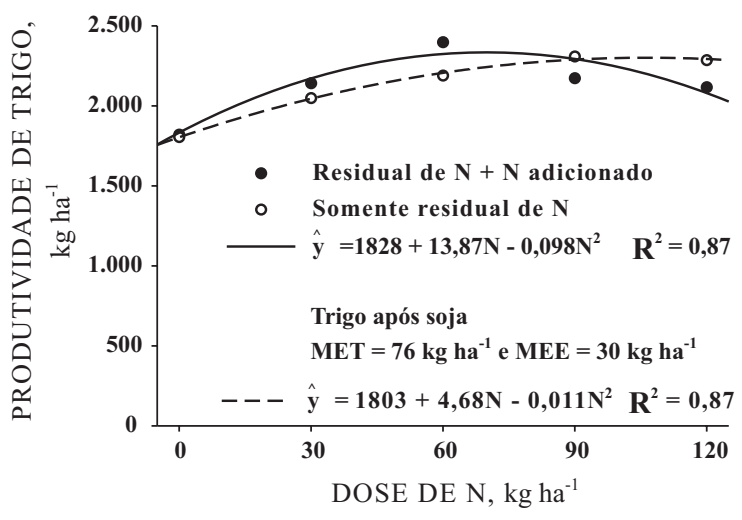

Figura 2. Produtividade de trigo após milho, como variável do residual de $\mathrm{N}$ aplicado no milho ((M1 + I1 + I2 + AP2)/4) e das doses de N aplicadas no trigo ((M1 + I1 + I2 + AP2)/4), máxima eficiência técnica (MET) e máxima eficiência econômica (MEE).

em cobertura é dependente das condições climáticas desde a semeadura até a época de aplicação (perfilhamento), além de considerar a expectativa de produtividade e a relação pi/pp, para tomada de decisão sobre a dose a ser aplicada.

\section{Produtividade de trigo após o milho como variável das doses de $\mathbf{N}$ mais o residual}

Em média, as produtividades de trigo após o milho, com utilização de doses de $\mathrm{N}$ no trigo, não foram superiores às obtidas com o residual de $\mathrm{N}$ aplicado no milho. No entanto, as curvas de resposta no primeiro caso tiveram inclinação maior, atingindo produtividade máxima com doses menores (Figura 2).

O experimento M1 apresentou pequena resposta à aplicação de $\mathrm{N}$, comportamento semelhante ao observado com o residual de $\mathrm{N}$ do milho, e a produtividade máxima $\left(1.869 \mathrm{~kg} \mathrm{ha}^{-1}\right)$ foi atingida com a dose de $58 \mathrm{~kg} \mathrm{ha}^{-1}$ (Quadro 5). No I2, a resposta foi mais acentuada $\left(13,89 \mathrm{~kg} \mathrm{ha}^{-1}\right.$ por $\mathrm{kg}$ de $\left.\mathrm{N}\right)$ do que no $\mathrm{M} 1$, e a produtividade máxima foi atingida com $77 \mathrm{~kg} \mathrm{ha}^{-1}$ de $\mathrm{N}$.

Novamente, a maior resposta ao $\mathrm{N}$ foi observada no experimento I2, que aumentou a produtividade em $1.063 \mathrm{~kg} \mathrm{ha}^{-1}$ com a dose de $82 \mathrm{~kg} \mathrm{ha}^{-1}$ de N. Nesse local, a resposta do trigo em resposta ao $\mathrm{kg}$ de $\mathrm{N}$ aplicado foi de 25,94 $\mathrm{kg} \mathrm{ha}^{-1}$ (Quadro 5), maior que a resposta encontrada anteriormente por Fontoura et al. (2000), que foi de $21,35 \mathrm{~kg} \mathrm{ha}^{-1}$ por $\mathrm{kg}$ de $\mathrm{N}$ aplicado.

$\mathrm{O}$ experimento AP2 apresentou pequena resposta às doses de $\mathrm{N}$ aplicadas no trigo, semelhante ao encontrado em resposta ao $\mathrm{N}$ residual do milho, porém a produtividade alcançada foi inferior à obtida utilizando apenas o residual.

Com utilização das doses de $\mathrm{N}$ no trigo, aliado ao residual deste nutriente da aplicação feita no milho (Quadros 4 e 5), o trigo respondeu, em média, até $71 \mathrm{~kg} \mathrm{ha}^{-1}$ de N (Figura 2), atingindo praticamente o mesmo rendimento obtido com o residual médio de $213 \mathrm{~kg} \mathrm{ha}^{-1}$ de $\mathrm{N}$ aplicado no milho (Quadro 2). Fontoura et al. (2000) encontraram resposta do trigo e cevada superior à observada neste trabalho, em que o fator "b" da equação ficou em torno de $20 \mathrm{~kg} \mathrm{ha}^{-1}$ após o milho. Neste experimento, as culturas apresentaram elevados rendimentos mesmo na ausência da aplicação de $\mathrm{N}$, indicando que as culturas tinham condições favoráveis para o crescimento e desenvolvimento e, possivelmente, menor residual de $\mathrm{N}$ aplicado no milho.

A MEE do trigo após o milho foi obtida com a dose de $30 \mathrm{~kg} \mathrm{ha}^{-1}$ de N (Figura 2), sendo um pouco inferior a essa dose no trigo após a soja. Contudo, nesse cálculo não foi considerado o efeito residual do $\mathrm{N}$ aplicado no milho. Possivelmente, a dose aumentaria um pouco para suprir esse residual.

Comparando os dados das figuras 1 e 2, pode-se observar semelhança na resposta média do trigo após o milho e a soja, em que a MET foi alcançada com a

Quadro 5. Equações da produtividade de trigo, coeficiente de determinação, dose de máxima eficiência técnica (MET) e produtividade máxima de trigo em função das doses de nitrogênio aplicadas no trigo mais o residual do nitrogênio aplicado no milho - safra de 2004

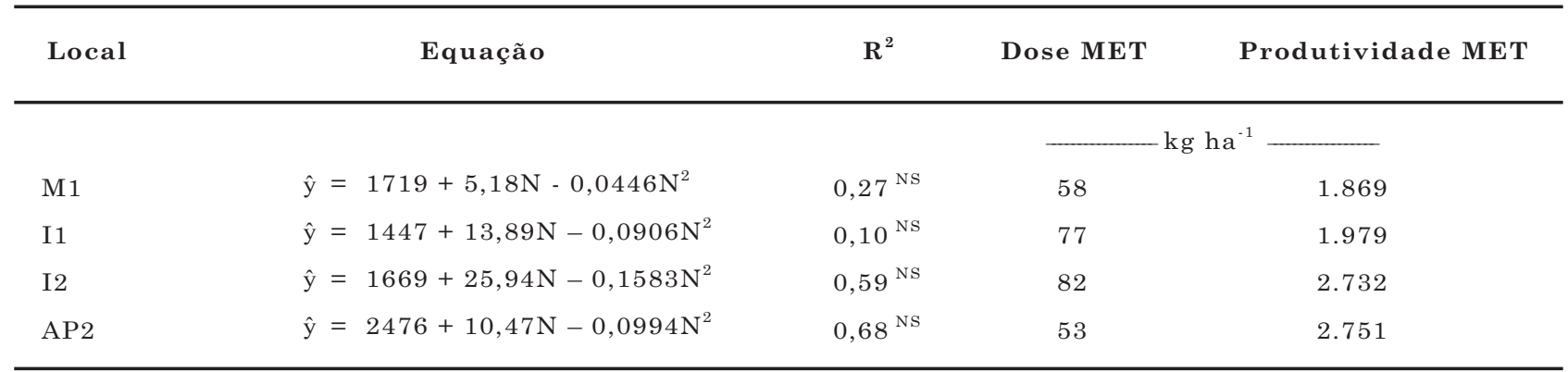

y: rendimento esperado, em kg ha ${ }^{-1}$; $\mathrm{N}$ d dose de nitrogênio, em kg ha-1; M1: Misiones 1; I1: Itapúa 1; I2: Itapúa 2; AP1: Alto Paraná

1; AP2: Alto Paraná 2. NS: não-significativos. 
dose de $71 \mathrm{~kg} \mathrm{ha}^{-1}$ de $\mathrm{N}$ após o milho, enquanto após a soja foi atingida com $76 \mathrm{~kg} \mathrm{ha}^{-1}$. A MEE também se apresentou muito semelhante nas duas situações, variando em apenas $5 \mathrm{~kg} \mathrm{ha}^{-1}$. Deve-se ressaltar que, no caso do trigo após o milho, havia efeito residual da fertilização do milho, sem o qual as doses de MET e MEE seriam acrescidas. Outro detalhe importante foram as produtividades alcançadas pelo trigo após as duas culturas, e a soja proporcionou melhores condições para o desenvolvimento e rendimento de trigo, quando comparada ao trigo após milho. Nessa última sucessão, pode-se concluir que a não-obtenção de rendimentos mais elevados não se deveu à deficiência de N, pois as doses aplicadas atingiram a MET.

A elaboração da recomendação de $\mathrm{N}$ para o trigo (Quadro 6) foi feita a partir dos dados experimentais obtidos neste experimento e com auxílio da literatura (Amado, 1997; IAPAR, 1998; CQFSRS/SC, 2004); ela foi ainda ajustada por técnicos e pesquisadores paraguaios durante reunião da RENALAS (2005). Assim, na recomendação da fertilização nitrogenada foram considerados vários fatores que interferem na produtividade do trigo, assim como sua instabilidade em relação a preços e custos de produção. É, pois, fundamental levar em consideração na tomada de decisão da fertilização nitrogenada do trigo: a cultura anterior; o teor de MO; a expectativa de produtividade; o acompanhamento da lavoura e o histórico de produtividade; a expectativa de preço do produto; e o preço do insumo.

Após o milho, a dose poderá ser reduzida em anos de baixa precipitação pluvial em até $30 \mathrm{~kg} \mathrm{ha}^{-1}$ de N, quando doses acima de $150 \mathrm{~kg} \mathrm{ha}^{-1} \mathrm{de} \mathrm{N}$ forem aplicadas no milho, porém é necessário cautela para não incorrer em deficiência, prejudicando a produtividade.

A tabela foi elaborada para a relação pi/pp de 8; variação de uma unidade nessa relação afeta em $5 \mathrm{~kg} \mathrm{ha}^{-1}$ a MEE, ou seja, se a relação pi/pp aumentar para $10\left(10-8=2: 2 \times 5=10 \mathrm{~kg} \mathrm{ha}^{-1}\right)$, então a dose econômica em qualquer das situações é $10 \mathrm{~kg} \mathrm{ha}^{-1}$ inferior.

É fundamental a utilização de uma quantidade de 15 a $20 \mathrm{~kg} \mathrm{ha}^{-1}$ de $\mathrm{N}$ na semeadura em linha, principalmente quando a cultura anterior for o milho. Dessa forma, aumenta-se a oferta de $\mathrm{N}$ mineral para as plantas, diminuindo a imobilização pelos microrganismos na decomposição da palhada com alta relação $\mathrm{C} / \mathrm{N}$. O período crítico do trigo, em que a cultura vai expressar seu potencial produtivo, vai da emergência até a sétima folha; o início desse período determina o número de espiguetas por espiga, e o final, o número de colmos por área (Bredemeier \& Mundstock, 2001).

O fator expectativa de produtividade deve ser cuidadosamente elaborado, pois atingir alta produtividade de trigo não depende somente da aplicação de N; devem-se considerar principalmente o histórico da lavoura e as condições climáticas. Basicamente, a expectativa vai modificar a dose de cobertura, fato que favorece a tomada de decisão, pois aos 30 dias após emergência é possível determinar com maior segurança a expectativa de produtividade.

\section{CONCLUSÕES}

1. A cultura do trigo responde economicamente à dose de $35 \mathrm{~kg} \mathrm{ha}^{-1}$ de N após a soja, para produtividade em torno de $3.100 \mathrm{~kg} \mathrm{ha}^{-1}$; após a cultura do milho, responde economicamente até a dose de $30 \mathrm{~kg} \mathrm{ha}^{-1}$, atingindo produtividade em torno de $2.100 \mathrm{~kg} \mathrm{ha}^{-1}$.

2. Em solo com teor de MO maior que $4 \%$ observase capacidade de suprimento de $\mathrm{N}$ pelo solo suficiente para alcançar produtividade de até $2.500 \mathrm{~kg} \mathrm{ha}^{-1} \mathrm{de}$ trigo, na ausência de adubação nitrogenada.

Quadro 6. Recomendação de adubação nitrogenada para o trigo sob sistema plantio direto no Paraguai

\begin{tabular}{|c|c|c|c|c|}
\hline \multirow{2}{*}{ Cultura anterior } & \multirow{2}{*}{ MO do solo } & \multicolumn{3}{|c|}{ Expectativa de produtividade $\left(\mathrm{kg} \mathrm{ha}^{-1}\right)$} \\
\hline & & $<2.000$ & $2.000-3.000$ & $>3.000$ \\
\hline & $\%$ & + & $\mathrm{kg} \mathrm{ha} \mathrm{he}^{-1} \mathrm{de}$ & - \\
\hline \multirow[t]{3}{*}{ Milho } & $<2$ & 60 & 80 & 100 \\
\hline & $2-3$ & 40 & 60 & 80 \\
\hline & $>3$ & 20 & 40 & 60 \\
\hline \multirow[t]{3}{*}{ Soja } & $<2$ & 40 & 60 & 80 \\
\hline & $2-3$ & 20 & 40 & 60 \\
\hline & $>3$ & 0 & 20 & 40 \\
\hline
\end{tabular}

Fonte: Wendling (2005), ajustada em Renalas (2005). 
3. $\mathrm{O}$ trigo respondeu à adubação residual de $\mathrm{N}$ aplicado no milho, elevando a produtividade em $500 \mathrm{~kg} \mathrm{ha}^{-1}$ com a dose estimada de $213 \mathrm{~kg} \mathrm{ha}^{-1}$ de N.

4. Para produção de trigo após o milho, num teor médio de MO (2-3\%), recomenda-se aplicação de $40 \mathrm{~kg} \mathrm{ha}^{-1}$ de $\mathrm{N}$ para expectativa de produtividade até $2.000 \mathrm{~kg} \mathrm{ha}^{-1}$ de trigo, $60 \mathrm{~kg} \mathrm{ha}^{-1}$ de $\mathrm{N}$ para expectativa entre $2.000-3.000 \mathrm{~kg} \mathrm{ha}^{-1}$ de trigo e $80 \mathrm{~kg} \mathrm{ha}^{-1}$ de $\mathrm{N}$ para expectativas acima de $3.000 \mathrm{~kg} \mathrm{ha}^{-1}$ de trigo. Em caso de teores baixos de $\mathrm{MO}(<2 \%)$, deve-se aumentar a quantidade em $20 \mathrm{~kg} \mathrm{ha}^{-1}$ de $\mathrm{N}$ em cada faixa de expectativa de produtividade. Para teores altos de MO (> $3 \%$ ), pode-se reduzir em $20 \mathrm{~kg} \mathrm{ha}^{-1}$ de $\mathrm{N}$ em cada faixa de expectativa de produtividade.

5. Quanto à produção de trigo após a soja, num teor médio de MO (2-3\%), recomenda-se aplicação de $20 \mathrm{~kg} \mathrm{ha}^{-1}$ de $\mathrm{N}$ para expectativa de produtividade até $2.000 \mathrm{~kg} \mathrm{ha}^{-1}$ de trigo, $40 \mathrm{~kg} \mathrm{ha}^{-1}$ de N para expectativa entre $2.000-3.000 \mathrm{~kg} \mathrm{ha}^{-1}$ de trigo e $60 \mathrm{~kg} \mathrm{ha}^{-1}$ de $\mathrm{N}$ para expectativas acima de $3.000 \mathrm{~kg} \mathrm{ha}^{-1}$ de trigo. Para teores baixos de MO $(<2 \%)$, deve-se aumentar a quantidade em $20 \mathrm{~kg} \mathrm{ha}^{-1}$ de $\mathrm{N}$ em cada faixa de expectativa de produtividade. Em se tratando de teores altos de MO (> $3 \%$ ), pode-se reduzir em $20 \mathrm{~kg} \mathrm{ha}^{-1} \mathrm{de}$ $\mathrm{N}$ em cada faixa de expectativa de produtividade.

\section{LITERATURA CITADA}

ALVAREZ V., V.H. Avaliação da fertilidade do solo: Superfície de resposta - modelos aproximativos para expressar a relação fator resposta. Viçosa, MG, Universidade Federal de Viçosa, 1991. 75p.

AMADO, T.J.C. Disponibilidade de nitrogênio em sistemas de cultura e preparo do solo. Porto Alegre, Universidade Federal do Rio Grande do Sul, 1997. 201p. (Tese de Doutorado)

BASSO, C.J. Épocas de aplicação de nitrogênio para milho cultivado em sucessão a plantas de cobertura de solo, no sistema plantio direto. Santa Maria, Universidade Federal de Santa Maria, 1999. 76p. (Tese de Mestrado)

BREDEMEIER, C. \& MUNDSTOCK, C.M. Estádios fenológicos do trigo para a adubação nitrogenada em cobertura. $R$. Bras. Ci. Solo, 25:317-323, 2001.

COMISSÃO DE QUÍMICA E FERTILIDADE DO SOLO CQFSRS/SC. Manual de recomendações de adubação e calagem para os estados do Rio Grande do Sul e Santa Catarina. Porto Alegre, SBCS - Núcleo Regional Sul, 2004. 394p.
DA ROS, C.O.; SALET, R.L.; PORN, R.L. \& MACHADO, J.N.C. Disponibilidade de nitrogênio e produtividade de milho e trigo com diferentes métodos de adubação nitrogenada no sistema plantio direto. Ci. Rural, 33:799-804, 2003.

FATECHA, A. Guía para la fertilización de cultivos anuales e perennes de la región oriental del Paraguay. Caacupé, Paraguay, Ministerio de Agricultura y Ganadería, Subsecretaria de Estado de Agricultura, Dirección de Investigación Agrícola., 1999. 23p.

FONTOURA, S.M.V.; ALMEIDA, J.L.; WOBETO, C.; RUGEL, H.; SATTLER, R.; SANDINI, I.E.; CLAZER, E.R. \& NOVATIZKI, M.R. Resposta de cereais de inverno à adubação nitrogenada em cobertura em função da précultura, na região de Entre Rios, Guarapuava/PR. In: FERTBIO 2000, Santa Maria. Anais. Santa Maria, 2000. CD ROM

GOEPFERT, C.F.; SALIM, H. \& MOURA, R.L. Experimento de níveis de $\mathrm{N}, \mathrm{P}$ e $\mathrm{K}$ e calcário, e do efeito residual da adubação e da manutenção com fósforo e potássio no rendimento de trigo em solo Camaquã. Agron. Sulriograndense, 10:179-188, 1974.

GRIMM, S.S. Aspectos econômicos da adubação. Porto Alegre, Universidade Federal do Rio Grande do Sul, 1970. 14p. (Boletim Técnico, 6)

INSTITUTO AGRONÔMICO DO PARANÁ - IAPAR. Recomendações técnicas para a cultura do trigo no Paraná - 1998. Londrina, 1998. 124p. (Circular, 100).

LERA, F.L.; CANTARELLA, H.; BOLONHEZI, D.; PEREIRA, J.C.V.N.; LARA-CABEZAS, W.H.R. \& TRIVELIN, P.C.O. Absorção pelo milho do nitrogênio aplicado antecipado ou em cobertura, em sistema de plantio direto. In: FERTBIO 2000, Santa Maria. Anais. Santa Maria, 2000. CD ROM

MUNDsTOCK, C.M. \& BREDEMEIER, C. Dinâmica do afilhamento afetada pela disponibilidade de nitrogênio e sua influência na produção de espigas e grãos de trigo. R. Bras. Ci. Solo, 26:141-149, 2002.

RED NACIONAL DE LABORATORIOS DE ANALISIS DE SUELO - RENALAS. Primero taller de control de calidad de los laboratorios de suelos e recomendación de fertilización nitrogenada, fosfatada e potássica para trigo, maiz e soja en siembra directa en Paraguay. Assunción, 2005. CD-ROM

ROSSATO, R.R. Potencial de ciclagem de nitrogênio e potássio pelo nabo forrageiro intercalar ao cultivo do milho e trigo sob plantio direto. Santa Maria, Universidade Federal de Santa Maria, 2004. 106p. (Tese de Mestrado)

TEDESCO, M.J.; GIANELLO, C.; BISSANI, C.A.; BOHNEN, H. \& VOLKWEISS, S.J. Análise de solo, plantas e outros materiais. Porto Alegre, Universidade Federal do Rio Grande do Sul, 1995.

WENDLING, A. Recomendação de nitrogênio e potássio para trigo, milho e soja sob sistema plantio direto no Paraguai. Santa Maria, Universidade Federal de Santa Maria, 2005. 124p. (Tese de Mestrado) 